\title{
Editorial
}

\section{Education for Creativity and Talent Development in the 21st Century}

\author{
Kirsi Tirri, ${ }^{1,2}$ Seokhee Cho, ${ }^{2}$ Doehee Ahn, ${ }^{3}$ and James R. Campbell ${ }^{2}$ \\ ${ }^{1}$ Helsinki Collegium for Advanced Studies, University of Helsinki, P.O. Box 4, 00014 Helsinki, Finland \\ ${ }^{2}$ Department of Administrative and Instructional Leadership, School of Education, St. John's University, 8000 Utopia Pkwy, \\ Jamaica, New York, NY, USA \\ ${ }^{3}$ Department of Education, Chung-Ang University, Seoul 06974, Republic of Korea
}

Correspondence should be addressed to Kirsi Tirri; kirsi.tirri@helsinki.fi

Received 26 October 2017; Accepted 26 October 2017; Published 16 November 2017

Copyright (c) 2017 Kirsi Tirri et al. This is an open access article distributed under the Creative Commons Attribution License, which permits unrestricted use, distribution, and reproduction in any medium, provided the original work is properly cited.

The world is facing challenges in the 21 st century that are very different from those in the previous centuries. Globalization, new technology, and knowledge growth in today's societies call for creative and purposeful citizens who can combine excellence with ethics. Gifted students and professionals in science create new ideas and products that can be used in the benefit of our society. However, the creative process in science includes many ethical issues that need to be considered before publishing the new idea or the product. A globalized tendency has been to reform education to nurture the 21st century competences of our youth.

The 21st century competences can be defined as an integration of knowledge, skills, attitudes, and values, which young people are required to have in the 21st century. Many international organizations, such as the United Nations Educational, Scientific and Cultural Organization, the Organization for Economic Cooperation and Development, and the European Union have published documents outlining educational goals for the 21st century emphasizing creativity as an important goal.

Meanwhile, international companies, for example, Intel Corporation and Microsoft Corporation, have collaborated with educators and educational institutions for developing frameworks for teaching and assessing the 21st century competences. The discussion of the 21st century competences has been an important topic in creativity and talent development research as well. In this discussion, creativity has been as one of the most important competences we should nurture in our youth.

The focus of this special issue is on the education for creativity and talent development in different fields including arts and humanities. This special issue is an international forum for researchers to summarize the most recent developments and ideas in the field, with a special emphasis given to the challenges of the 21st century creativity.

In the article "Creativity as a Stepping Stone towards Developing Other Competencies in Classrooms" by N. Ahmadi and M. Besançon from France, the main objective is to review the literature on creativity considering the other 21st century skills as well. The main hypothesis of the article is that the introduction of creative practices in classroom can possibly lead to developing other competencies of pupils at the same time. The review of the literature is based mostly on the theatrical link between creativity and critical thinking, between creativity and metacognition, and, last, between creativity and collaboration skills. Finally, the authors discuss these findings considering teachers' training and the nature of classroom activities.

In the empirical study of 607 Finnish students "How Do School Children and Adolescents Perceive the Nature of Talent Development? A Case Study from Finland" by E. Kuusisto et al., the authors report results on the relation between implicit beliefs on intelligence and giftedness and students' academic achievements. The findings reveal that growth-oriented views about intelligence, but fixed ideas about giftedness, indicated higher math grades. The results suggest that the relationship between implicit beliefs and academic outcomes might not be as straightforward as previous studies have suggested.

Two of the articles investigate creativity and mathematical ability. The study from Taiwan "Threshold Effects of Creative 
Problem-Solving Attributes on Creativity in the Math Abilities of Taiwanese Upper Elementary Students" by C.-Y. Lin investigated the typology of the math creative problemsolving abilities of 409 fifth- and sixth-grade Taiwanese students. A Creative Problem-Solving Attribute Instrument was also devised with the aim of measuring students' perceptions on their motivation, knowledge, and skills, both in general and in specific domains. The results suggest a threshold effect from several attributes-divergent thinking, convergent thinking, motivation, general knowledge and skills, domain-specific knowledge and skills, and environment-on students' creative problem-solving abilities.

The article from Finland "Hands-On Math and Art Exhibition Promoting Science Attitudes and Educational Plans" by $\mathrm{H}$. Thuneberg et al., investigated the differences in experiences of learning mathematics between the contexts of school and an informal Math and Art Exhibition. The study participants $(N=256)$ were 12 -13-year-olds from Finland. The lowest achieving group appreciated the exhibition alternative for math learning compared to learning math at school. The boys considered the exhibition to be more useful than the girls as it fostered their science and technology attitudes. However, for the girls, the attractiveness of the exhibition, the experienced situation motivation, was much more strongly connected to the attitudes on science and technology and the worthiness of mathematics. Interestingly, the pupils experienced that even this short informal learning intervention affected their science and technology attitudes and educational plans.

The case study from the Netherlands "Preparing Students for Global Citizenship: The Effects of a Dutch Undergraduate Honors Course" by I. W. Schutte et al., investigates effects on the participating students $(N=25)$ of an undergraduate honors course, aimed at global justice citizenship. The Ethical Sensitivity Scale Questionnaire and the Global Citizenship Scale were used in a pre- and posttest design to measure possible development in the moral and civic domain among the participants of the course. Quantitative results show increased ethical sensitivity as well as global civic engagement and global competence among the participants. Qualitative results point in the same direction and provide deeper insights in the content of students' learning and the perceived impact of the course on their attitudes and behavior. Results are discussed in relation to theory on justice-oriented global citizenship and honors pedagogies.

Taken together, all the articles in this special issue address the importance of education for creativity and talent development in different fields, contexts, and countries. The editors of this issue are delighted to see the diverse conceptual and methodological approaches in these studies and encourage the researchers to further widen their approaches in the growing field of creativity and talent development research.

Kirsi Tirri

Seokhee Cho

Doehee Ahn

James R. Campbell 


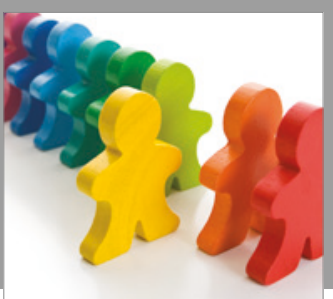

Autism

Research and Treatment
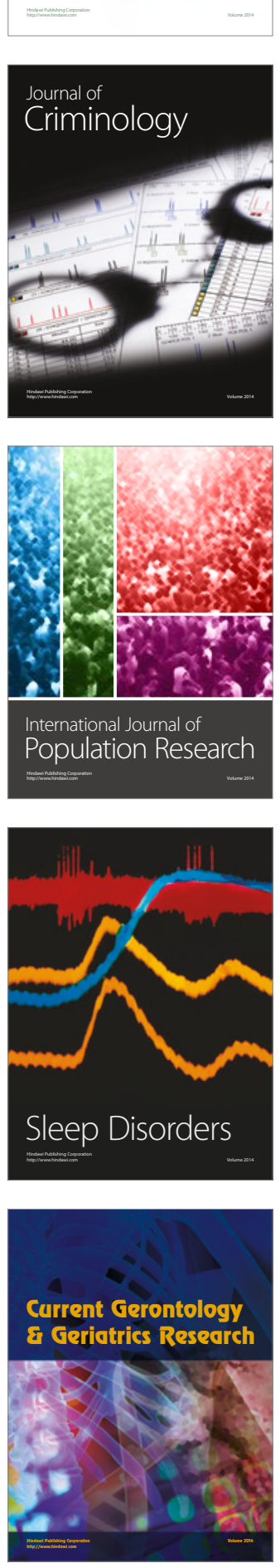

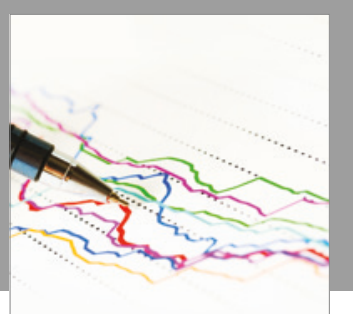

Economics

Research International

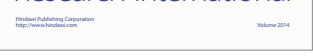

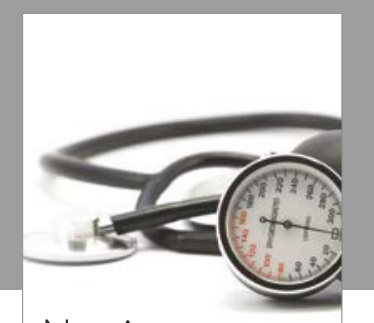

Nursing

Research and Practice

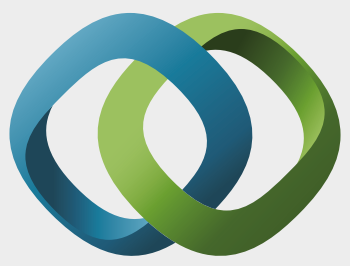

\section{Hindawi}

Submit your manuscripts at

https://www.hindawi.com
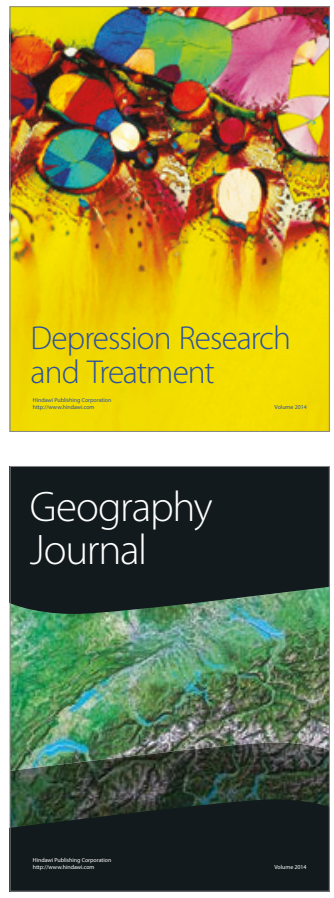
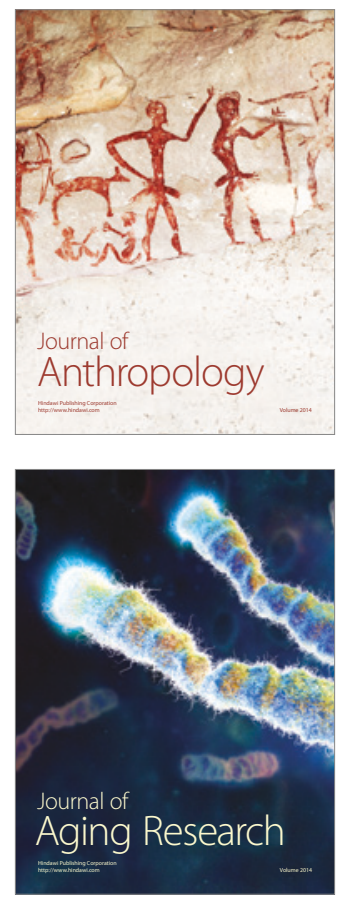
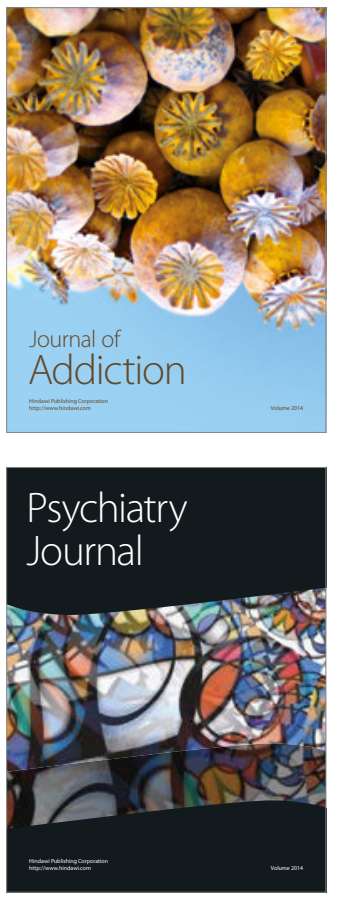

Child Development

Research

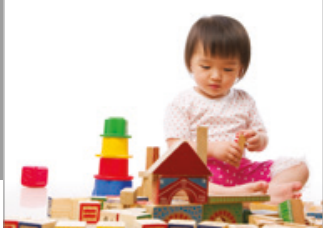

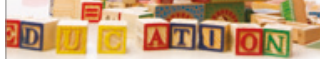
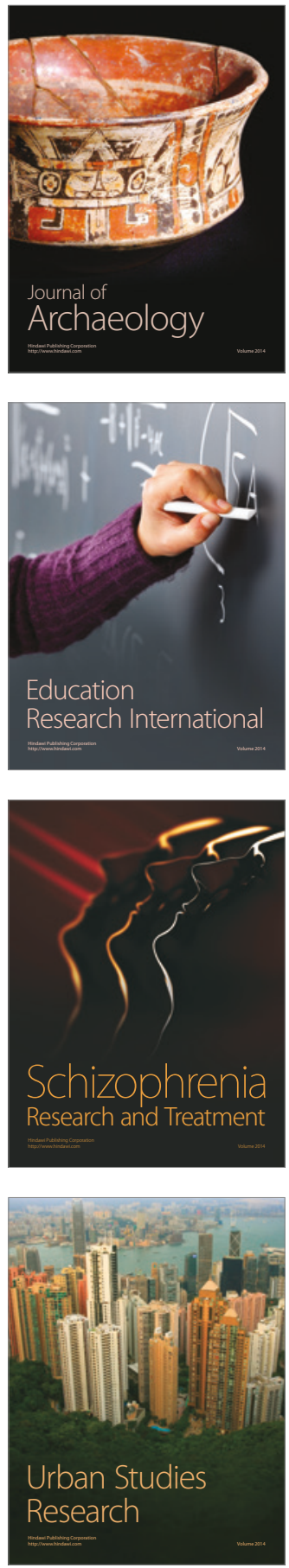